\title{
Pensar la escalada de violencia y la violencia en escalas. Entramados de la "lucha antisubversiva" pre-dictatorial. Bahía Blanca, 1974/1976
}

\author{
Thinking about scaling-up of violence and violence on \\ scale. Frames of the so-called "anti- subversive struggle". \\ Bahía Blanca, 1974/1976
}

\author{
Ana Belén Zapata \\ Universidad de Buenos Aires/ \\ Consejo Nacional de Investigaciones Científicas y Técnicas \\ (Argentina) \\ aymarazapata@yahoo.com.ar
}

\section{Resumen}

Desde los primeros meses de 1974 comenzaron a vivirse hechos de violencia en Bahía Blanca que tuvieron como víctimas a estudiantes y docentes universitarios, trabajadores, delegados obreros y militantes de izquierda y del peronismo de izquierda. En este artículo nos proponemos reconstruir parte de ese entramado represivo que impactó en la ciudad en los años previos al golpe de estado de 1976, caracterizando la violencia estatal y paraestatal que -fundada en la llamada "lucha antisubversiva"- imprimió el terror entre algunos sectores específicos de la sociedad que la sufrieron directamente. En este artículo no solo nos proponemos reconstruir históricamente aspectos claves sobre la violencia política entre 1974-1976, sino también dilucidar qué nuevas cuestiones sobre la violencia en la "lucha antisubversiva" podemos iluminar desde la apuesta por reducir la escala de observación.

Palabras Clave: Violencia política - Violencia paraestatal - Triple A - Bahía Blanca 


\begin{abstract}
From the beginning of 1974, the citizens of Bahia Blanca suffered situations of repressive violence that took university students and professors, workers and worker delegates, leftist and left Peronism activists, as their victims. In this article we propose to reconstruct part of this repressive framework that struck the city during the years before the coup of 1976. Our goal is to characterize the state and paramilitary violence that -founded in the "fight against subversion"-, printed on terror in the streets of Bahia Blanca and among specific social sectors that suffered it directly. In this article we propose not only a historical reconstruction of some key aspects of political violence between 1974-1976, but also to clarify what are the new issues that we can illuminate by reducing the scale of observation.
\end{abstract}

Key Words: Political violence - Paramilitary violence - "Triple A" - Bahía Blanca

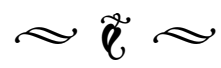

Un redactor del diario Noticias comparaba a Bahía Blanca con el "far west de las películas yanquis" en una nota de junio de 1974 cuando narraba un tiroteo entre tres hombres que perseguían a un cuarto sobre la calle Donado de esa ciudad. Entre las versiones locales sobre el hecho, algunos vecinos detallaban al diario que el episodio era parte de enfrentamientos internos sostenido entre "distintos grupos de los servicios de seguridad de sindicalistas que hasta el presente tienen un poder hegemónico dentro de la CGT local". ${ }^{1} \mathrm{Y}$ que el hecho en cuestión tenía relación con "la detención de dos guardaespaldas del diputado nacional Rodolfo Ponce”, producida hacía unos días. ${ }^{2}$

Desde los primeros meses de 1974, se comenzaron a vivir hechos de violencia en Bahía Blanca que tuvieron como víctimas a estudiantes y docentes universitarios,

1. Diario Noticias, 22/06/1974.

2. Diario Noticias, 22/06/1974.

142 trabajadores, delegados obreros y militantes de izquierda y del peronismo de izquierda. Muchas de estas situaciones fueron denunciadas por las víctimas como parte del accionar de grupos de choque con anclajes o relación de dependencia en instituciones como la Universidad Nacional del Sur (UNS) o la Confederación General del Trabajo (CGT) Regional, cuando ambas instituciones eran dirigidas por figuras políticas de la derecha y del peronismo ortodoxo a saber, por un lado el interventor de la universidad, el rumano filo fascista Dionisio Remus Tetu ${ }^{3}$ y por el otro Rodolfo Ponce, ${ }^{4}$ uno de los principales

3. Dionisio Remus Tetu era un militante rumano de la organización filo fascista Guardia de Hierro. Estudió en 1a Universidad de Budapest y fue docente del ex Instituto Tecnológico del Sur de Bahía Blanca, de la UNS y del instituto Juan XXIII. Colaboró desde varios trabajos con la Corporación del Comercio y la Industria de Bahía Blanca y con el diario local La Nueva Provincia, propiedad de la familia Massot.

4. Rodolfo Ponce era uno de los sindicalistas más 
impulsores de la "depuración" interna del movimiento peronistas de los considerados sectores "infiltrados de izquierda".

En este artículo nos proponemos reconstruir parte de ese entramado represivo que impactó en la ciudad en los años previos al golpe de estado de 1976, caracterizando la violencia estatal y paraestatal que -fundada en la llamada "lucha antisubversiva"- imprimió el terror en las calles de Bahía Blanca y entre ciertos sectores sociales específicos que la sufrieron directamente.

Partimos del análisis del fenómeno en una escala de lo local pero proponiendo un constante diálogo con la escala de la política nacional. Consideramos que esta operación genera un terreno fértil para pensar en su complejidad la violencia política y el accionar de organizaciones, que si bien operaron en espacios situados, admitieron nexos de conexión con bandas de lógicas similares en otros puntos del país. De igual forma, este diálogo de escalas nos permite comprender la relación entre los grupos de choque y el poder político; cómo convivieron estas bandas con las fuerzas represivas "legales"; de qué forma se dieron las condiciones de posibilidad para su accionar y cómo se proveyeron de recursos y logística desde instituciones públicas que funcionaron como "unidades de apoyo" o "bases operativas".

La lectura en escala reducida de análisis nos permite llegar a tramas complejas que

importantes de la ciudad en Bahía Blanca por estos años, dentro de la línea de sindicatos peronistas de tendencia ortodoxa. Provenía de la Unión de Recibidores de Granos y Afines de la Argentina (URGARA), lideraba la CGT Regional y fue elegido Diputado Nacional por el bloque del Frente Justicialista de Liberación (FREJULI) no lograríamos dilucidar desde miradas más alejadas o desde una operación "porteñocéntrica" que, amplificando lógicas construidas estrictamente para Capital Federal, las generaliza de forma acrítica al orden nacional. Consideramos, que si bien algunas explicaciones sobre la violencia paraestatal de la época resuelven el tema aludiendo sólo a la tan nombrada "Triple A", 5 a la luz de nuevas reconstrucciones históricas para distintos puntos del país, surgen aportes y caracterizacionesque amplían elestadoactualde conocimiento sobre la temática. ${ }^{6} \mathrm{Y}$ en términos

5. La "Triple A" o "Alianza Anticomunista Argentina” fue una organización paraestatal estructurada en el Ministerio de Bienestar Social en coordinación con la Policía Federal Argentina, la Secretaría de Inteligencia del Estado y algunos sindicatos desde donde se realizaron acciones criminales. Según Horacio Salvador Paino, si bien estaba comandada por el ministro de Bienestar Social José López Rega, también fue coordinada por el comisario Alberto Villar, por Juan Ramón Morales, Rodolfo Eduardo Almirón y Miguel Ángel Rovira, miembros de la Policía Federal. Véase PAINO, Horacio, Historia de la Triple A, Editorial Platense S.A, Montevideo, 1984. Esta organización buscó acabar con quienes consideraban parte de la "subversión apátrida", y fijó sus víctimas en ámbitos muy diversos como personalidades de la política, legisladores, sacerdotes, obreros, sindicalistas etc. Se conoce que utilizaba la revista del peronismo más ortodoxo, El Caudillo de la Tercera posición, dirigida por Felipe Romeo para publicar amenazas y anunciar sus futuras víctimas. $\mathrm{Al}$ respecto véase $\mathrm{BESOKY,} \mathrm{Juan} \mathrm{Luis,} \mathrm{"La} \mathrm{revista} \mathrm{El}$ Caudillo de la Tercera Posición: órgano de expresión de la extrema derecha”, en Conflicto Social, Buenos Aires, 2010, No 3, Año 3, pp. 7-28.

6. Véase los aportes de Juan Iván LADEUIX sobre la CNU en Mar del Plata: LADEUIX, Juan Iván, "La Mazorca de Perón: prácticas e ideologías de la derecha peronista. Una aproximación a partir de un estudio de caso. Mar del Plata 1970-1976", ponencia presentada en X Jornadas Interescuelas/Departamentos de Historia, Rosario, 2005; las reconstrucciones de Laura Rodríguez Agüero sobre el Comando Moralizador Pio XII y el CAM en Mendoza: RODRÍGUEZ AGÜERO, Laura, "Ciclo de protestas, experiencias organizativas y represión paraestatal. Mendoza, 1972-1976”, Tesis de Doctorado 
historiográficos esto significa un esfuerzo por demás fructífero entendiendo que, como sostiene Nora Pagano, "el empleo de escalas espaciales ha favorecido la multiplicación de sólidos estudios sobre la historia provincialregional-local, en cuyo tratamiento se entrecruzan dimensiones económicas, políticas y culturales, ejemplificando sobradamente la discontinuidad de los fenómenos sociales y resignificando el intrincado tema de la 'historia nacional'". ${ }^{7}$

Por todo lo ya dicho, en este artículo no sólo nos proponemos reconstruir históricamente algunos aspectos clave sobre la violencia política en Bahía Blanca entre 1974-1976, sino también dilucidar ¿qué nuevas cuestiones sobre la violencia en la "lucha antisubversiva" podemos iluminar desde la apuesta por reducir la escala de observación?

\section{Escalada de la violencia y miedo cotidiano}

Entre 1974 y 1976, ocuparon numerosas

en Historia Universidad Nacional de La Plata, 2013; el trabajo de Pablo Scatizza sobre la violencia paraestatal en Neuquén: SCATIZZA, Pablo, "La Norpatagonia argentina bajo la Doctrina de Seguridad Nacional. Represión, dictadura y juicios de lesa humanidad: la causa Reinhold", Tesis de doctorado en Historia, Universidad Torcuato Di Tella, 2013; y los aportes de Hernán Merele sobre la "depuración" del peronismo en el partido de General Sarmiento: MERELE, Hernán, "Notas sobre la "Triple A" y la represión en el período constitucional 1973- 1976", ponencia presentada en VII Jornadas de Trabajo sobre Historia Reciente, UNLP, 2014.

7. PAGANO, Nora, "La producción historiográfica reciente: continuidades, innovaciones, diagnósticos", en DEVOTO, Fernando (director) Historiadores, ensayistas y gran público. La historiografía argentina 1990-2010, Biblos, Buenos Aires, 2010, p. 61. páginas de la prensa local las notas sobre brutales asesinatos $\mathrm{y}$ atentados $\mathrm{o}$ sobre hallazgos de cuerpos sin vida que aparecían en zonas alejadas del centro de la ciudad. Eran pocos los datos que acompañaban estas notas, sin embargo, en muchas de ellas, aparecía una somera descripción de las víctimas que por lo general referían a su condición de estudiante de la Universidad Nacional del Sur, o de obreros y/o, en menores casos, referían a la militancia o pertenencia político-partidaria. Es decir, encontramos ciertas características comunes entre las víctimas: se trataba "de militantes de izquierda o del peronismo de izquierda, de obreros y -en su mayoría- de estudiantes de la UNS con algún tipo de participación en la política estudiantil. Algunos fueron secuestrados de sus casas y luego encontrados con numerosos impactos de bala en sus cuerpos tirados mayormente en lugares comunes, todos en las afueras de Bahía Blanca”. ${ }^{8}$

Otras noticias comunes eran los estallidos de explosivos en locales partidarios como los del Partido Socialista de los Trabajadores (PST) o del Partido Comunista (PC), en casas de docentes de la Universidad Tecnológica Nacional (UTN) o en las viviendas de sacerdotes tercermundistas del Instituto Juan XXIII. También se conocieron las amenazas mecanografiadas y firmadas con las "AAA" dirigidas a conocidos abogados laboralistas a nivel local así como también a distintos docentes de la UNS. En resumidas cuentas, parte de la población bahiense vivió con terror estas noticias; pero también experimentó una suerte de "cotidianeidad del miedo" generado

8. ZAPATA, Ana Belén, "Violencia parapolicial en Bahía Blanca, 1974-1976. Delgados límites entre lo institucional y lo ilegal en la lucha contra la 'subversión apátrida'”, en Anos 90, Rio Grande do Sul, 2012, V. XIX, No 35, p. 121. 
por la circulación de patotas armadas que recorrían con distintos vehículos las calles de la ciudad. Particularmente, uno de los automóviles más recordados era el Fiat 125 celeste, bautizado popularmente -sobre todo por el sector obrero- como la "fiambrera de la CGT”.

Este último dato no es menor. Para el colectivo obrero de Bahía Blanca, el grupo de choque que recorría las calles era claramente identificable. Entre los trabajadores "el miedo estaba direccionado hacia su propia central obrera a la que 'nadie quería ir', no querían siquiera pasar cerca de Mitre y Rodríguez". ${ }^{9}$ Pero hacia principios de 1975, cuando algunos de los miembros de esta patota-que respondía a la CGT de Rodolfo Ponce- fueron contratados como "personal de vigilancia" de la UNS por el rector Remus Tetu, fue en el ámbito de esta universidad ${ }^{10}$ donde se comenzó a vivir de forma más cercana ese mismo terror. ${ }^{11}$

9. Corresponde a las calles en las que estaba situada la CGT de Bahía Blanca. Vid. ZAPATA, Ana Belén, "Andamios de experiencias: Conflictividad obrera, vigilancia y represión en Argentina. Bahía Blanca, 19661976", Tesis de Doctorado en Historia, Universidad Nacional de La Plata, 2014.

10. Cabe aclarar que ya en septiembre de 1974 los estudiantes de otra universidad local, la UTN, habían sufrido la ocupación del edificio por estos mismos "matones".

11.Alberto Rodríguez era estudiante de la carrera de Contador en los '70, también era militante de la Federación Juvenil Comunista en la UNS. Asimismo era un actor local agremiado en la Asociación Argentina de Actores. La pertenencia de Rodríguez hacia estos sectores perseguidos marcó su lectura sobre los hechos de violencia de la época:

“- Esta gente comienza a meterse a través del Secretario General de la CGT es la cabeza visible de la organización, de donde se emplean, de donde parten los autos de la esquina de Mitre y Rodríguez que estaba la CGT ahí tenían su lugar de operar siempre. Ellos
Los casos de dos asesinatos puntuales resultaron emblemáticos para el sector obrero y el sector estudiantil de la zona. Estos fueron, por un lado, el crimen en septiembre de 1974 contra el obrero de la construcción, delegado de obra y militante del Frente Antiimperialista por el Socialismo (FAS), Jesús “Negrito" García. Y por el otro lado, en abril de 1975, el asesinato del estudiante de la UNS, David "Watu" Cilleruelo, militante de la Federación Juvenil Comunista (FJC) y recientemente designado como secretario de la Federación Universitaria del Sur.

Alrededor de las 4 de la mañana de la madrugada del 22 de septiembre de 1974, un grupo de personas, anunciando ser "de la Policía”, ingresaron bruscamente en la casa de Jesús García y, “arrastrándolo y golpeándolo, lo suben a un automóvil Dodge Polara color verde". ${ }^{12}$ Luego se llevaron a Jesús, pero su

empiezan siendo un grupo de los más cercanos a Ponce, [Jorge] Argibay era la mano derecha de él en el sindicato de Recibidores de granos.

- ¿Qué hacía Argibay ahí?

- Sí, sí, fundamentalmente trabajaba como custodio de Ponce y después te voy a comentar algo más. Y él con otros empieza repartiendo volantes primero...

- ¿Volantes de qué?

- Hablo de Triple A. Hablando de que a los zurdos los van a reventar. Comienzan con eso en la vereda de la Universidad a repartir esos volantes. Lo que pasa es que uno los veía y eran de 40 años, ponele. Y nosotros a los 20 años lo que veías era a un viejo... repartiéndole volantes a los estudiantes te causaba gracia... Después siguen las provocaciones, se meten un día en la universidad pintan las paredes con la "Triple A" también, el hall central y empiezan a aparecer armados. Ya comienzan a portar armas y a mostrarse... pesados".

Entrevista de la autora a Alberto Rodríguez, realizada el 09/06/2012.

12. Causa no 7777. Legajo No 96 - Juzgado en lo Penal No 3 a cargo del Dr. Hugo Canallaro. "García Luis Jesús, víctima de homicidio calificado en Bahía Blanca”- 
hermana, testigo de los hechos, reconoció que el mismo vehículo que se lo llevó "se utilizaba por la CGT de esta ciudad". ${ }^{13}$ Horas después del secuestro, el cuerpo del "Negrito" fue encontrado en un paraje conocido como "el Pibe de Oro" por un chofer de ómnibus de la línea 512 que terminaba su recorrido. El cuerpo tenía varios impactos de bala en la cabeza.

A David "Watu" Cilleruelo lo asesinaron a sangre fría en los pasillos de la Universidad Nacional del Sur, a la vista de decenas de estudiantes que se encontraban presentes porque aquel 3 de abril de 1975 era un día de inscripción en las materias. Los testigos del hecho declararon a la justicia que, cuando Cilleruelo repartía volantes invitando a la asamblea de la Federación Universitaria del Sur, se le acercó Jorge Argibay (uno de los custodios del rector Remus Tetu), le pidió sus documentos, y como él se negó a dárselos, le disparó en la nuca. Uno de los compañeros de militancia de Watu recordaba: "Yo soy uno de los primeros que regresa y me encuentro con Watu. Se arrima Argibay, se arrodilla, lo da vuelta y lo reconozco a Watu, me apunta y me dice 'pobrecito, se golpeó la cabeza contra la pared". ${ }^{14}$

Estos dos casos en particular resultan significativos por lo que generaron en los colectivos militantes a los que pertenecían las víctimas. Luego del asesinato del "Negrito", una movilización sin precedentes se organizó en repudio por el hecho. La misma nucleó a

septiembre 1974.

13. Ibídem.

14. Video documental "Watu, ¿sabes quién fue?".

Testimonio de Miguel Pereyra, testigo presencial del asesinato de Watu.

146 amplios sectores de trabajadores, militantes de izquierda y del peronismo de la Tendencia quienes cargaron su cajón marchando por las calles de la ciudad mientras denunciaban: "Ponce asesino del Negrito García"; "Ponce traidor a vos te va a pasar lo mismo que le pasó a Vandor"; "Cinco por uno no va a quedar ninguno". ${ }^{15} \mathrm{El}$ caso de "Watu", por el contrario, resultó para la militancia estudiantil fuertemente disciplinador. Según lo que explicaba uno de los compañeros de "Watu": "El clima con la "Triple A" no impactó en la Universidad hasta lo de "Watu", ahí es como que la Universidad se termina ahí... digamos la efervescencia militante. Fue un quiebre. Quebró la militancia universitaria. O sea que lo que buscaron lo lograron". ${ }^{16}$

\section{Política legislativa local y nacional: la violencia detrás del discurso}

$\mathrm{El}$ cruce de niveles o escalas para pensar un fenómeno situado resulta ineludible, siempre lo que es "local" se constituye en función de una relación con aquello que está "por fuera" de esa escala. Elizabeth Jelin y Ponciano del Pino advierten que "al estudiar lo local, está presente también lo nacional y lo global, ya que lo que sucede en esos escenarios tiene interlocutores y es parte de realidades más amplias -regional, nacional y mundial-y al mismo tiempo también más pequeñas (el barrio, la familia, el pueblo o comunidad). De ahí la importancia de analizar la dinámica de relación entre estos niveles". ${ }^{17}$

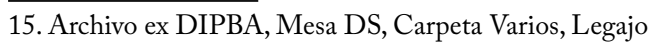
$\mathrm{n}^{\circ} 2024$.

16. Entrevista a Alberto Rodríguez, Op. Cit.

17. DEL PINO Ponciano y JELIN, Elizabeth, Luchas locales, comunidades e identidades, Siglo XXI, Madrid, 2003, p. 6. 
Esta dinámica o relación entre niveles queda evidenciada por ejemplo en los sentidos que le da una comunidad específica a los sucesos que la afectan en lo cotidiano, influidas por las informaciones que provienen de otros lugares. Observamos estas influencias en la manera en que impactaron -para el caso- las noticias nacionales sobre hechos de violencia.

Por ejemplo, si analizamos los debates dentro del ámbito del Concejo Deliberante de Bahía Blanca, encontramos que en las actas de sesiones quedaron cristalizados los repudios frente a atentados y hechos criminales. Pero es interesante ver cómo las intervenciones de ciertos concejales comenzaron como formas de repudio hacia hechos que sucedían alejados a la ciudad, para poco a poco ir convirtiéndose en instancias de denuncia concreta por atentados y situaciones de violencia política dentro del plano local. En el caso del concejal Carlos Galassi de la UCR podemos ver cómo se expresaba en la sesión del 7 de mayo de 1974:

Señor presidente, toda vez que fue necesario, nuestro partido ha repudiado cualquier tipo de hecho de violencia que se diera en el ámbito del país. En este momento, en especial los radicales de Bahía Blanca, vemos con preocupación la sucesión de hechos violentos que se están dando en esta ciudad. A partir de problemas, que parecieran exclusivamente universitarios, este tipo de hechos ha trascendido ese ámbito, que no por ello deja de ser grave aun circunscripto a ese lugar, sino que han llegado a la calle, al ámbito de la ciudad, y eso es lo que nos preocupa enormemente... La presencia de grupos armados en la Facultad Tecnológica Regional es un índice de la gravedad que está teniendo esta circunstancia en Bahía Blanca; el ataque de que fueran víctimas un grupo de jóvenes estudiantes adictos a un determinado partido -en actitud proselitista o de propagandizar un acto determinado - es un hecho grave que tiene que alarmarnos.... ${ }^{18}$

Días más tardes desde el bloque del FREJULI, los concejales Gerardo Carcedo y Marta Bustos realizaban un homenaje a Carlos Mugica con motivo de su asesinato. Marta Bustos relacionaba hechos locales con otros en diversos puntos del país:

Manifiesto mi mayor repudio a aquellos asesinos, que son los mismos que mataron a tantos compañeros en Ezeiza, que continúan tiroteando a nuestros jóvenes compañeros en las unidades básicas, que colocaron bombas en todos los locales de la juventud y que siguen matando en Bahía Blanca, Buenos Aires y en toda la República a miles de jóvenes. Son los mismos que tirotean a los estudiantes por la noche, cuando vienen a hacer reclamos... ${ }^{19}$

Por su parte, Carcedo aludía al accionar de la "Triple A" en Córdoba tras el asesinato de Atilio López, pero observaba la situación local con la extrañeza con la que se observa lo que resulta novedoso.

Bahía Blanca, una ciudad pacífica, una ciudad de hombres que trabajan, se ha convertido en un foco de violencia. ¿Cuándo ha existido la violencia en Bahía Blanca?; se la fabrica artificialmente porque se está tratando de crear caos, porque en el caos es donde los pescadores oportunistas sacan ventajas políticas. Aquí se terminó la época

18. Diario de Sesiones del Concejo Deliberante, Municipalidad de Bahía Blanca, Acta del 7 de mayo de 1974.

19. Diario de Sesiones del Concejo Deliberante, Municipalidad de Bahía Blanca, Acta del 14 de mayo de 1974. 
de las ventajas políticas; los argentinos tenemos que defender la Constitución y la ley con las armas si es necesario. Yo sé que estas palabras son graves, pero hay que decirlas; porque mañana si llega a pasar algo con el gobierno del pueblo, que queden perfectamente identificados aquellos que se callaron porque tenían miedo, o los que hablaron aunque eso involucrara un riesgo. ${ }^{20}$

En noviembre de 1974, dentro del Concejo Deliberante, se planteó una concreta denuncia por el atentado que sufrió la concejala Bustos, militante del peronismo barrial y parte de una familia de trabajadores ligados a la Tendencia, específicamente a la Juventud Trabajadora Peronista, ${ }^{21}$ cuando un grupo armado baleó el frente de su casa. Carcedo en esta oportunidad declaraba: "Le correspondió en este caso, a una militante del Movimiento Peronista, concejala de este Cuerpo y miembro de esta bancada, que no está presente por razones de salud; le tocó el turno a ella. La semana pasada bandas armadas ametrallaron la residencia donde vive ella y su familia". ${ }^{22}$ La violencia deja de ser vista como algo que sucede en espacios lejanos o capitalinos, para sufrirse de manera palpable entre los propios legisladores bahienses.

20. Diario de Sesiones del Concejo Deliberante, Municipalidad de Bahía Blanca, Acta del 17 de septiembre de 1974. Estas palabras de Gerardo Carcedo, dichas en 1974, adquieren otra dimensión hoy que sabemos que fue desaparecido en 1976 durante la dictadura militar.

21.La familia Bustos era conocida por su militancia dentro del ámbito de la construcción. Hasta enero de 1974 Roberto Bustos (hermano de Marta y líder local de la JTP) había sido secretario general de la UOCRA Bahía Blanca.

22. Diario de Sesiones del Concejo Deliberante, Municipalidad de Bahía Blanca, Acta del 26 de noviembre de 1974.

148
Para el caso del ámbito legislativo del orden nacional, en la Cámara de Diputados de la Nación -y puntualmente a partir de la presencia de Rodolfo Ponce en la banca del FREJULIobservamos que algunas de sus iniciativas políticas y legislativas tuvieron su contracara en situaciones concretas de violencia. Es decir, la tarea legislativa de Rodolfo Ponce estuvo por momentos imbricada con hechos de violencia justificados en la llamada "lucha antisubversiva".

Esto último lo podemos ver desde la disputa por la sanción de la Ley de Asociaciones Profesionales. ${ }^{23}$ Ponce, como uno de los más vehementes defensores del proyecto, tuvo una fuerte discusión con el legislador Héctor Sandler -diputado por el partido Unión del Pueblo Argentino (UDELPA)- cuando éste último durante una intervención en la Cámara relacionó directamente el atentado que había sufrido el senador Hipólito Solari Yrigoyen en noviembre de 1973 con su disertación crítica -dentro de la Cámara de Senadores- respecto a

23. Esta ley favoreció claramente a los sectores de la burocracia y la ortodoxia sindical en dos sentidos, por un lado la Ley de Asociaciones Profesionales permitía que los cargos sindicales se prolonguen de dos a cuatro años; por otro lado también habilitaba la intervención de seccionales sindicales locales desde sus centrales. Federico Lorenz planteaba al respecto: "Con la sanción de esta Ley, los sindicatos agrupados en las 62 organizaciones' y la CGT se garantizaban tanto el financiamiento como el rol de únicos interlocutores frente al gobierno y los empresarios. La extensión del período de obligatoriedad para convocar asambleas apuntaba a cerrar los caminos para la democracia sindical, mientras que el establecimiento del Ministerio de Trabajo como la instancia suprema para dirimir cualquier conflicto entre afiliados y sindicatos daba a la conducción cegetista un eficaz elemento de presión, dado que el ministro de Trabajo era Ricardo Otero, de la UOM". Vid. LORENZ, Federico, Los zapatos de Carlito. Una historia de los trabajadores navales de Tigre en la década del setenta, Grupo Norma, Buenos Aires, 2007, pp. 98-99. 
la posibilidad de sanción de dicha ley. Sandler sugería que el atentado al senador había tenido que ver con haber hecho pública su oposición a la Ley de Asociaciones Profesionales. Ante esa denuncia un enérgico Rodolfo Ponce reclamó por lo que entendió una acusación infundada de Sandler hacia el sector del oficialismo que defendía esa ley. Cabe la mención de que el atentado a Solari Yrigoyen fue considerado la "carta de presentación" de la "Triple A".

En la misma lógica (pero en otra escala), con la sanción de esta ley hubo consecuencias concretas en el ámbito sindical de la ciudad de Bahía Blanca, ya que dicha ley en vigencia posibilitó la intervención de la Unión Obrera de la Construcción (UOCRA) de Bahía Blanca (dirigida por Roberto Bustos y filiada con la Juventud Trabajadora Peronista-JTP) por parte de la dirigencia nacional del gremio. Esta intervención se produjo en enero de 1974 y a pocos días de la efectiva sanción de la ley. La misma representó el avance de la ortodoxia peronista sobre una de las seccionales que eran consideradas "díscolas". Este hecho no solo podría enmarcarse en el proceso de “depuración” interna del peronismo -por el cual bregaba Ponce- sino que también resultó uno de los hechos inaugurales de la violencia local con el saldo de un obrero de la JTP asesinado en un enfrentamiento que se dio por causa de dicha intervención. Por su parte, en esta ocasión, Ponce apoyó enteramente a los interventores que llegaron a Bahía Blanca, expresando su afinidad con el sector de la ortodoxia en clara disidencia y enfrentamiento con la gestión de Bustos.

Otro de los proyectos encarados por Rodolfo Ponce en la Cámara de Diputados fue la propuesta de la creación de una
Universidad Nacional Sindical. En la sesión parlamentaria del 19 de junio de 1973, Ponce presentó un proyecto para crear una universidad exclusiva para trabajadores. El objeto de la institución era el de "propiciar el acceso de los trabajadores sindicalmente organizados y sus hijos a la capacitación de nivel universitario medio y superior". ${ }^{24} \mathrm{El}$ proyecto proponía un órgano rector, que era la "Asamblea Gremial Universitaria" conformada por un delegado titular y uno suplente de cada asociación profesional confederada y asimismo sería presidida por el secretario general de 1a Confederación General del Trabajo. Las atribuciones de esa asamblea serían: dictar estatuto de universidad, elegir rector, crear carreras, decidir intervenciones, planeamiento general, determinación de la orientación general de la enseñanza, entre otras. Tendría también un "Consejo Directivo Gremial Universitario" conformado por doce miembros elegidos por la Confederación General del Trabajo de la República Argentina. El artículo $15^{\circ}$ del proyecto estipulaba que "la sede del gobierno de la Universidad Nacional Sindical Argentina estará ubicada en la ciudad de Bahía Blanca, provincia de Buenos Aires". 25

Recién hacia marzo de 1974 , ese proyecto fue estudiado por el ministro de trabajo, Ricardo Otero. Sin embargo, para septiembre de 1974, Ponce explicaba ante la revista de la ortodoxia sindical, El Caudillo de la Tercera Posición - revista en la cual aparecía habitualmente en notas sobre su persona -las razones por las cuales ese proyecto finalmente se había disuelto:

24. Diario de sesiones de la Cámara de Diputados de la Nación, Acta del 19 de junio de 1973.

25. Ibídem. 
Cuando nosotros con el compañero José Ignacio Rucci hicimos un proyecto para crear la Universidad Nacional Sindical y le pedimos la venia al General para que tuviera sanción de nuestro bloque, Perón nos manifestó que no era necesario crear otra Universidad cuando ya teníamos desde 1952 la Universidad Obrera a la que después del '55 se le cambió el nombre por el de Tecnológica. Nos dijo que lo que hacía falta no era un proyecto sino la recuperación de un principio: las Universidades Obreras para capacitar a los trabajadores argentinos. ${ }^{26}$

Debemos entender en este contexto el proceso que Ponce encaró en septiembre de 1974 para "recuperar" para la CGT el control político de la UTN de Bahía Blanca que estaba siendo dirigida por sectores estudiantiles y docentes ligados a la Tendencia. Estos hechos visibilizaron de manera notoria a la patota de Rodolfo Ponce que tenía una activa incidencia en la UTN. Por esas situaciones, estudiantes y docentes denunciaron públicamente que "personas con armas largas" habían robado la urna de un proceso eleccionario interno y amedrentaron con violencia a los alumnos de esa casa de estudio. En relación a estos hechos, se produjo un nuevo enfrentamiento entre Ponce y Sandler dentro de la Cámara de Diputados. Sandler denunció la presencia de "los matones a sueldo" que había visto ocupar la UTN de Bahía Blanca, luego de un viaje que había hecho a la ciudad. Manifestaba Sandler:

Es exacto que en la Universidad Tecnológica debe ser para los trabajadores; es exacto que como ocurre ahora, esté tomada por matones que no son trabajadores. He estado reunido con todos los grupos estudiantiles, incluyendo los que pertenecen al peronismo

26. El Caudillo, No43, 13/09/1974. y todos me han dicho lo mismo. En la Universidad del Sur también he recogido la misma verdad. Todo el mundo dice lo mismo. Si el diputado Ponce cree que puede instaurar una nueva Chicago en la Argentina está absolutamente equivocado, porque el pueblo de la República va a hacerse respetar. ${ }^{27}$

Se podría pensar que fueron estos enfrentamientos que tuvo Héctor Sandler tanto con Rodolfo Ponce -como los que tuvo también con Felipe Romeo director de la revista El Caudillo- los que le costaron una amenaza de la "Triple A". Sandler recibió la amenaza a los pocos días de su viaje a Bahía Blanca, el 11 de septiembre de 1974 en su estudio de Capital Federal. Sandler optó por exiliarse fuera del país frente a las advertencias de la "Triple A".

\section{Los recursos públicos que sostienen la actividad paraestatal}

El acercamiento de la escala de análisis permite complejizar la cuestión del anclaje estatal en los recursos e insumos de los grupos parapoliciales. Si hasta el momento se conocía la participación del Ministerio de Bienestar Social de José López Rega en cuanto al financiamiento y aportes estructurales para la "lucha antisubversiva", desde una mirada en escala local encontramos que por fuera de la esfera capitalina de Buenos Aires, también hubo otras instituciones estatales que funcionaron como enclaves organizacionales y de aprovisionamiento de recursos y logística para las tareas "antisubversivas" de los grupos de choque.

27. Diario de sesiones Congreso de la Nación, Cámara de diputados, Acta del 4 de septiembre de 1974. 
Luego de la asunción de Oscar Ivanissevich en la cartera del Ministerio de Cultura y Educación, éste señaló la necesidad de "depurar ideológicamente" ${ }^{28}$ las universidades nacionales. En una oportunidad, durante una reunión que Ivanissevich mantuvo con distintos rectores universitarios se trató el tema de los comedores "que funcionan en las universidades nacionales de Córdoba, Salta, Comahue, Bahía Blanca, Litoral (Santa Fe), Rosario, La Pampa, San Luis, Cuyo y del noroeste. $\mathrm{El}$ ministro preguntó a los rectores de esas casas de estudios, si deben subsistir o no los comedores universitarios y si puede considerárselos como focos de subversión". ${ }^{29}$ En este contexto, de la llamada "misión Ivanissevich", Dionisio Remus Tetu, asumió en diciembre de 1974 la intervención en la Universidad del Comahue y en febrero de 1975 de la Universidad Nacional del Sur en Bahía Blanca.

Tetu inmediatamente contrató "personal afectado al servicio de vigilancia y seguridad" 30 para los edificios de esas casa de estudios. En concreto para la UNS, algunos de ellos provenían del ámbito sindical y laboral portuario, eran ex o actuales trabajadores de la Junta Nacional de Granos, otros tenían formación militar en la Armada o eran ex policías de la provincia de Buenos Aires. Esa era la composición del grupo contratado por

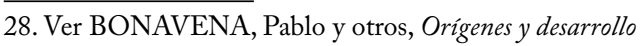
de la guerra civil en Argentina. 1966-1976, Oficina de publicaciones CBC, Buenos Aires, 1998; IZAGUIRRE, Inés y ARISTIZÁBAL, Zulema, Las luchas obreras 1973 - 1976, Documento de Trabajo, 17, Instituto de Investigaciones Gino Germani, Buenos Aires, 2000.

29. Diario Rio Negro, 03/02/1975.

30. Res. No132-UNS, 25/03/1975.
Tetu dentro del ámbito universitario bahiense.

Este grupo de la UNS, además de seguir las directivas de Remus Tetu, era liderado por Jorge Oscar Argibay, quien fuera también custodio de Rodolfo Ponce para la CGT. Desde la resolución que le dio organicidad al grupo hoy podemos saber cuánto dinero les abonaba a cada uno de ellos el Estado. La resolución de contratación marcaba que: "El señor Jorge Oscar Argibay percibirá como remuneración... la suma de $\$ 5.000,00$ mensuales... Cada uno de los restantes agentes contratados... percibirá una remuneración única y global de $\$ 4.000,00 \ldots .{ }^{31}$

La investigación que se abrió por el asesinato del estudiante David Cilleruelo ${ }^{32}$ en los pasillos de la UNS, permitió conocer que este grupo utilizaba autos y armas provistas desde la Universidad; que tenían una dedicación horaria específica como en cualquier otro cargo público; e incluso es posible dar cuenta de ciertas internas entre los miembros de este grupo de "seguridad" de la UNS. Es decir, algunos marcaban sus diferencias o distancias con el grupo que comandaba Argibay; de esta forma se alejaban convenientemente del círculo de influencias de Argibay en el marco de una instancia judicial que ubicaba al líder del grupo en la escena del crimen contra Cilleruelo.

En la causa también se mostraba que en ocasiones solían dormir en el mismo rectorado "cuando temían por algún ataque

31. Res. No132-UNS, 25/03/1975.

32. L863-E3-Expte. 174-9-11 - Juzgado Federal de $1^{\circ}$ Instancia de Bahía Blanca "Homicidio cometido en la Universidad Nacional del Sur - Víctima David Hover Cilleruelo- 9 de abril 1975. 
a la universidad". También acompañaban a Tetu, como sus "guardaespaldas", en los reiterados viajes que el rector hacía a Neuquén por sus responsabilidades en la Universidad del Comahue. Otro dato importante, son las menciones del contacto con Raúl Guglielminetti a quien algunos de los miembros señalaban como el "jefe de seguridad" de la Universidad del Comahue. ${ }^{33}$ Esto nos permite pensar en las conexiones regionales entre estos miembros del grupo de choque de Tetu, la articulación entre estas dos universidades como bases operativas y la estructuración de una "depuración" universitaria que admitió puntos de contacto a escala interprovincial.

Por otra parte, la motivación ideológica en la conformación de este grupo de choque por parte de Remus Tetu aparece dentro de la causa por el asesinato de Watu Cilleruelo cuando el juez consulta respecto a quién le habría proporcionado los datos, nombres y apellidos de los integrantes del "servicio de seguridad" de la universidad, para que finalmente Tetu los contratara. En respuesta, el rector interventor dijo que algunos de ellos se habían presentado espontáneamente como ex empleados de la Universidad Tecnológica, y como ésta había "enfrentado problemas

33. Al respecto de la situación en la Universidad de Comahue, Pablo Scatizza reconstruye que "al mismo tiempo en que Tetu expulsaba trabajadores y estudiantes de la universidad, incorporó una legión de matones que seguirían fielmente sus órdenes represivas. Tal como se desprende de la Resolución 'I' 0411 del 14 de abril de 1975, el interventor contrató, a raíz de la 'necesidad de contar con custodia de los edificios de esta Universidad' a un grupo de sujetos que formarían ni más ni menos que el grupo de choque de la Triple A en la región. Entre ellos estaba el tristemente célebre represor Raúl Guglielminetti”. Ver SCATIZZA, Pablo, "La Norpatagonia argentina bajo la Doctrina de Seguridad Nacional...", Op. Cit., p. 127. subversivos antes que la UNS” eso valió como antecedente para contratar a esas personas con el fin de ocuparse de "mantener el orden dentro de la universidad". Otros nombres le habían llegado desde contactos con ex integrantes de las fuerzas armadas y de seguridad y de los servicios de inteligencia.

Por lo pronto, estas personas que conformaban el "personal de seguridad" en UNS, eran vistos por los estudiantes como los sujetos que constantemente los amedrentaban.

Yo de lo que me acuerdo es de ir por el pasillo desde el ala de ingeniería hasta el hall central y ver venir dos tipos y dije ¡uh! Mira que loco que traen ahí unos palos de plumeros deben ser de ordenanza... En serio que lo pensé. Me pasa que después uno de ellos me dicen que era Argibay, me pasa que se me da por mirar así iy eran metralletas! $Y$ la otra fue, la vez que tuvimos la reunión en el palomar... Que accedes por unas escaleritas chiquititas... Nosotros estuvimos reunidos ahí, yo ahí cursaba Latín me acuerdo, o Cultura Clásica. Estuvimos reunidos como hasta las 10 de la noche, con una ingenuidad total. Cuando bajamos, salimos del aula y empezas a bajar y hasta prácticamente la puerta del aula había pintadas de las Tres A.... Es más, el mural del Watu ¿por qué se puso ahí? Porque es el primer lugar donde las Tres $\mathrm{A}$ hacen su primera pintada. ${ }^{34}$

\section{La "lucha antisubversiva" del Estado}

Luego del establecimiento del estado de

34. Entrevista de la autora a Graciela Luscky (estudiante Letras en años '70, ex militante de FJC), realizada el $16 / 09 / 2012$. 
sitio en noviembre de 1974, las fuerzas policiales fueron las principales responsables de realizar los llamados "operativos antisubversivos" en todo el país entre 1974 y 1975.

En Bahía Blanca, también se replicó esta dinámica que aparecía diariamente publicitada en La Nueva Provincia, el diario local que detallaba los operativos. A fines de 1974, en un operativo las autoridades de la delegación local de la Policía Federal, allanaron una casa, secuestraron armas y detuvieron a dos personas a las que procesaron por el artículo 189 bis del Código Penal. ${ }^{35} \mathrm{~A}$ los pocos días más tarde, la policía de la Comisaría $1^{\circ}$ detuvo a once personas por considerarlas parte de "una célula extremista" y por el secuestro de libros, folletos, revistas consideradas "material subversivo" además de armas. ${ }^{36}$ En febrero de 1975, luego de uno de los llamados "procedimientos antisubversivos" la policía local allanó la vivienda de un estudiante y según los medios le secuestraron "material explosivo y bibliográfico de carácter subversivo". En ese operativo se detuvieron dos personas. ${ }^{37} \mathrm{Y}$ el 22 de agosto la Unidad Regional 5 de Policía confirmó otro "procedimiento antisubversivo" ahora el barrio de Tiro Federal. ${ }^{38}$

José Daniel Dallochio era el comisario jefe de la Unidad Regional $\mathrm{V}$ de policía de Bahía Blanca y fue quien desde esta fuerza y públicamente comenzó a hablar de la necesidad de pasar de la "represión a la prevención", haciendo alusión no solo a la llamada "lucha antisubversiva", sino también

35. Diario La Nueva Provincia, 01/12/1974.

36. Diario La Nueva Provincia, 05/12/1974.

37. Diario La Nueva Provincia, 01/02/1975.

38. El Diario para el pueblo, 22/08/1975. a su tarea contra la delincuencia "común". En concreto, durante una conferencia de prensa detallaba que se habían detenido a miembros de una banda por reiterados hurtos, a personas que violaban la ley de juegos prohibidos y a mujeres en situación de prostitución. ${ }^{39}$

Sin embargo, fue luego de un conjunto de decretos presidenciales y directivas emitidas desde el Consejo de Defensa, que se establecieron a nivel nacional los lineamientos claves para la articulación en todo el territorio nacional de una lucha contra el "enemigo interno a la Nación”. Así se impulsó la participación y la actuación mancomunada de todas las fuerzas armadas y de seguridad, ya no sólo las fuerzas de la policía provincial y federal. Con el decreto 2770/75 de octubre de 1975, quedó constituido el Consejo de Seguridad Interna y el Consejo de Defensa presidido por el ministro de Defensa e integrado por los comandantes generales de cada una de las Fuerzas Armadas, cuerpos que debían "coordinar con las autoridades nacionales, provinciales y municipales, la ejecución de medidas de interés para la lucha contra la subversión". ${ }^{40} \mathrm{El}$ decreto 2771/75 posibilitaba el establecimiento de convenios entre el Consejo de Defensa y los gobiernos de las provincias para subordinar las policías y servicios penitenciarios provinciales "para su empleo inmediato en la lucha contra la subversión". ${ }^{41} \mathrm{El}$ decreto 2772/75 estipulaba que, desde el Consejo de Defensa, se realizarían las operaciones militares y de seguridad para "aniquilar" a los "elementos subversivos" en todo el territorio nacional.

39. El Diario para el pueblo, 03/08/1975.

40. Decreto 2770/75, 6 de octubre de 1975.

41. Decreto 2771/75, 6 de octubre de 1975. 
Esos decretos se instrumentaron desde la "Directiva del Consejo de Defensa No 1/75 (lucha contra la subversión)". En la "Directiva No 404/75 (lucha contra la subversión)", Jorge Rafael Videla, a la sazón Comandante General del Ejército, consignó cuáles serían los plazos estipulados para llevar a cabo la "aniquilación del enemigo". ${ }^{42}$

Todas estas disposiciones tuvieron su expresión en el plano local desde el trabajo en conjunto de las distintas Fuerzas Armadas y policiales. Los operativos que antes sólo realizaban las fuerzas policiales, a principios de noviembre se comenzaron a anunciar desde la prensa como "ejercicios antisubversivos" para la zona que involucraban a efectivos del Ejército, la Armada, la Prefectura Naval Argentina y la Policía de la Provincia de Buenos Aires. Hacia fin de año, el Comandante de Operaciones Navales Luis María Mendía, establecía públicamente que "el adiestramiento y las operaciones de lucha contra la subversión pasarán a tener absoluta prioridad" ${ }^{43}$ Mendía anunciaba a la población bahiense por medio de la prensa que él y sus hombres pretendían luchar incluso "hasta dar la vida" en pos de "lograr el total exterminio de la subversión". ${ }^{44}$

42. Desde esta directiva se proyectaba que: "La ofensiva debe permitir: a) Disminuir significativamente el accionar subversivo para fines del año 1975. b) Transformar la subversión en un problema de naturaleza policial para fines de 1976. c) Aniquilar los elementos residuales de las organizaciones subversivas a partir de 1977. 4) El esfuerzo principal de la ofensiva será ejercido sobre los grandes centros urbanos y áreas colindantes a lo largo del eje: TUCUMAN-CÓRDOBA-SANTA FE- ROSARIO- CAPITAL FEDERAL Y GRAN BUENOS AIRES- LA PLATA- BAHÍA BLANCA".

43. Diario La Nueva Provincia, 29/11/1975.

44. Ibídem.

154
Si bien como consecuencia de los decretos de aniquilamiento, las fuerzas armadas y policiales comenzaron a actuar en conjunto en la zona, también resulta interesante observar qué sucedía en este contexto con la actuación de las bandas paraestatales y su convivencia con las fuerzas represivas "legales". Para el caso local, observamos lo complejo de esas situaciones de co-existencia, incluso cuando en apariencia las dos formas represivas bregaban por la lucha contra un "enemigo en común", contra el "enemigo subversivo". En ese sentido, hacia octubre de 1975, encontramos indicios de pujas entre ambos sectores, que se expresaban desde reclamos del sector paraestatal por mayor dureza en el accionar represivo de la policía bonaerense, a la cual le reclamaban que:

...se dedicaron a realizar ridículos, burdos e infantiles procedimientos $\mathrm{y}$ detenciones fugaces que movieron de risa, pero que provocaron la lógica inquietud en los sectores hacia los que estaban dirigidos, posibilitando de este modo la reactualización de las condiciones y aranceles a satisfacer para que la autoridad policial haga la vista gorda. Merced a eso es que nuevamente reinan en Bahía Blanca la prostitución, el juego y se mueven con soltura e impunidad los corruptos de toda laya... ${ }^{45}$

Vemos que pese a tener en apariencia similares objetivos, existieron por momentos enfrentamientos y criterios dispares en la concreción de la llamada "lucha antisubversiva". Estos son algunos matices que podemos

45. Comunicado firmado por el COMANDO PIO XII. Este comunicado -según conclusiones de los agentes de la DIPBA- correspondía a los grupos armados que respondían tanto a Rodolfo Ponce como a Remus Tetu. En Archivo ex DIPBA, Mesa DS, Carpeta Varios, Legajo $n^{\circ} 4291$. 
realizar desde una mirada situada localmente, esta permite complejizar la cuestión de las relaciones internas entre las fuerzas policiales y militares y los grupos de choque de origen paraestatal.

\section{Algunas ideas finales}

Sabemos que "desde los años '90, las cuestiones de escala se vieron enriquecidas a partir de la implementación de la variación o juegos de aquellas, concepto que posibilitó el desarrollo de indagaciones capaces de vincular dimensiones macro y micro sociales. Un buen ejemplo lo constituye la biografía, en la que el individuo se convierte no sólo en una lente privilegiada para dar cuenta del medio social y la época sino para conectar dimensiones particulares individuales y colectivas". ${ }^{46}$ También las dimensiones individuales permiten echar luz, respecto a cómo pensar la violencia paraestatal y su relación con la estatal, y las modalidades de pasaje de ciertas formas represivas hacia otras diferenciables. Algunos vasos comunicantes resultan más evidentes cuando nos enfocamos en la clave biográfica, por ejemplo. Si revisáramos las trayectorias de algunos de los miembros del grupo de contratados por la Universidad Nacional del Sur y por Remus Tetu, podríamos ver que ciertos derroteros los encuentran luego de 1976 “reciclados" por la dictadura y contratados por el V Cuerpo de ejército como Personal Civil de Inteligencia.

Otra trayectoria biográfica que también nos muestra puntos de continuidad es la

46. PAGANO, Nora, "La producción historiográfica reciente...”, Op. Cit., p. 60. de Félix Alejandro Alais, señalado desde la declaración del ex oficial de la Policía Federal, el "arrepentido" Rodolfo Peregrino Fernández, como miembro del Grupo Villar dentro de la estructura de la "Triple A" ${ }^{47}$ Alais aparece mencionado dentro del testimonio de Fernández como uno de los responsables del atentado del diputado Rodolfo Ortega Peña. Por otra parte, Félix Alais llegó a Bahía Blanca en 1975 a instancias de Carlos Guillermo Suarez Mason, quien para entonces era su cuñado y jefe del V Cuerpo de Ejército en la ciudad. En 1976, Alais fue nombrado subcomisario de la Policía Federal en Bahía Blanca. Siguiendo esa trayectoria, podemos pensar en los vínculos entre Dionisio Remus Tetu y su grupo de choque, con este subcomisario -sindicado como miembro de la "Triple A" antes del golpe de Estado-. Los puntos de contactos quedan en evidencia cuando en agosto de 1976, Félix Alais -ya dentro de la Policía Federal y junto a Adel Vilas y al comisario Carlos María Baldovinodenunciaban en una conferencia de prensa a 17 profesores de la UNS por considerados culpables de "convertir a la universidad en una usina subversiva". ${ }^{48}$ Entre los docentes acusados, figuraban muchos de los nombrados en una de las sentencias a muerte que se había hecho pública en 1974 y que aparecía firmada

47. Especificaba Fernández: "El grupo de Villar fue una de las principales vertientes en la formación de la Alianza Anticomunista Argentina (AAA)... Posteriormente, pese al retiro de Villar, el grupo permanece cohesionado y en operatividad bajo el liderazgo de su inspirador. Del entorno de Villar integran las Tres A, el principal Jorge Muñoz, el inspector Jorge M. Veyra, el inspector Gustavo Eklund, el subinspector Eduardo Fumega, el inspector Alejandro Alais, el principal Bonifacio, el inspector Félix Farías y el principal retirado Tidio Durruti". FERNÁNDEZ, Peregrino Rodolfo, Autocrítica policial, CID Editor, Buenos Aires, 1983, pp. 10-11.

48. Diario La Nueva Provincia, 05/08/1976. 
por la "Triple A". Aquí las continuidades aparecen en los sujetos que participaron de la represión paraestatal previa al golpe y luego lograron insertarse dentro de la trama represiva del terrorismo de Estado post 1976.

Establecer un diálogo constante entre escalas de análisis nos permite. No sólo ampliar el conocimiento sobre cómo se suscitó la dinámica de la "lucha antisubversiva" en distintos puntos del país, sino también dar cuenta de las conexiones entre grupos de choque que operativamente se establecieron para tal fin.

Esta última cuestión también evidencia la importancia de no dar por sobreentendido el anclaje territorial o espacial desde el cual se analiza este problema, o cualquier otro.

Hablar sobre la "Triple A" solamente desde los parámetros que definieron su forma de operar en Capital Federal y pretender leer en eso la violencia paraestatal de la época en escala nacional, resulta -cuanto menosalgo problemático. Hernán Merele ya nos alertaba de lo incierto de equiparar en este tipo de estudios, contextos y hechos tan disímiles como "el asesinato del sacerdote Carlos Mugica, cometido en Capital Federal a mediados de 1974, con los crímenes contra prostitutas cometidos en Mendoza por el Comando Depurador Pío XII a fines de 1975".49 Definitivamente se desdibujarían muchos problemas al operar desde esa lógica. Nos perderíamos de pensar en las configuraciones de los grupos de choque en distintas localidades; en las conexiones regionales entre ellos; en el nivel de autonomía

49. MERELE, Hernán, "Notas sobre la Triple A...”, Op. Cit., p. 14. o no de sus operaciones; en la elección de sus víctimas; en su provisión de recursos; en sus relaciones con el poder político, y podríamos seguir.
Recibido: 13/03/2015

Aceptado: 23/06/2015

Publicado: 31/07/2015 